\title{
Analysis of Limit Setting Force of Casing Inside Slips Based on Cylindrical Shell Theory
}

\author{
Yinping Cao*, Shaokai Tong and Yihua Dou \\ Xi'an Shiyou University, Xi'an, Shaanxi, 710065, China
}

\begin{abstract}
Casing will be damaged in a well because of the setting force, and may even be broken when the force is too large. To clearly demonstrate the interaction of the mechanism of packer and casing, a mechanical model of casing as thin-wall cylinder was established with the consideration of the axial force and additional bending moment induced by the bending of casing near the slips of packer. And, the equation of limit setting force on the casing exerted by slips was deduced by bending moment theory of cylindrical shell. The relationships of the limit setting force of N80, P110, TP140 casing and thickness were analyzed. It was found that the bending stress and the hoop stress were the biggest near the bottom of the slips, and that position was the dangerous section. The limit setting force of casing exerted by slips increased with the thickness of casing, when the packer and the outer diameter of casing remained the same. And the limit setting force was higher in high grade casing. The limit setting force calculated in this paper was decreased by $5 \%$ to 14 $\%$ than by thick-wall theory, and it is deduced to be safer. The method proposed in the paper can be used to evaluate the limit setting force and provide the basis for the choice of hanging load.
\end{abstract}

Keywords: Casing, cylindrical shell theory, limit setting force, packer in well testing, slips.

\section{INTRODUCTION}

In recent years, there are many accidents such as collapse of casing caused by packer slips. Fracture of the slips itself, sealing failure of rubber, cut of hydraulic anchor malfunction, creep of downhole string and the leakage of wellhole, occurring frequently in oilfields during the process of setting, acid fracturing and well opening [1,2]. Research on packer slips includes the analysis of contact stress between slip and casing $[3,4]$, structure optimization design of new slips [5], and simulation of casing damage due to cut of slips in laboratory [6]. But there should be a further study on the interaction mechanism between slips and casing. In the previous analysis before, the distribution of radial force was assumed uniform or the radial displacement kept the same [7-9] but because of the bending moment and axial tensile forces acting on the slips, we should also consider to them to accurately evaluate the limit setting force. Whether the casing should be taken as thin-wall cylinder or thick-wall cylinder relies on the steel grade as well as the ratio of diameter of the casing and thickness of the wall. Taking 5 1/2 inch P110 casing as example, the general thicknesses are $6.99 \mathrm{~mm}, 7.72 \mathrm{~mm}, 9.17 \mathrm{~mm}, 10.54 \mathrm{~mm}$, $12.09 \mathrm{~mm}$, and $13.46 \mathrm{~mm} \mathrm{[10].} \mathrm{When} \mathrm{the} \mathrm{ratio} \mathrm{of} \mathrm{outer} \mathrm{diameter}$ of the casing and thickness is larger than 26.22, the casing should be taken as a thin-wall cylinder and when the ratio of outer diameter of the casing and thickness is less than 12.44 by the standard of API BUL 5C3 and mechanic of cylinder, it should be taken as a thick-wall cylinder. In this paper, the interaction of casing and packer was analyzed and the formula of the limit setting force of casing was deduced with the casing taken as thin-wall cylinder [11].

*Address correspondence to this author at the Xi' an Shiyou University, Xi'an, Shaanxi, Dianzi Er Road, Xi'an, 710065, China; Tel: +86-13636815042; E-mail: caoyinping029@163.com

\section{ESTABLISHMENT OF THE MECHANICAL MODEL OF CASING EXERTED BY PACKER SLIPS USED IN WELL TESTING}

The casing bears the weight and radial pressure of slips when setting. The distribution of the contact stress between casing and slips was assumed uniform and the friction coefficient was constant, so the mechanical model of the casing was a thin-wall cylinder subjected to uniform pressure, bending moment and weight. The radial contact stress between the slips of packer and casing was obtained as:

$$
p_{r}=K \cdot \frac{Q}{n l d_{c} \sin \beta_{k}}
$$

where, $K$ is the transverse load coefficient, $Q$ is the axial force of packer, $n$ is the number of the pieces of slips, $l$ is the length of slips, $d_{c}$ is the inner diameter of casing,$\beta_{k}$ is half the angle of the tooth surface of slips.

The deformation differential equation of casing exerted by packer slips under the action of radial uniform pressure $p_{r}$ and axial force $Q$ can be expressed as follows by the theory of bending moment of cylindrical shell [12].

$$
\nabla^{4} u+4 \beta^{4} u=\frac{p_{r}}{E I}+\frac{v Q}{2 \pi \bar{R}^{2} E I}
$$

where, $u$ is the radial displacement of Casing exerted by packer slips along $x$ direction, $\beta=\left[\frac{3\left(1-v^{2}\right)}{\bar{R}^{2} \delta^{2}}\right]^{\frac{1}{4}}$ is the 
geometric parameters of the casing, $E I=\frac{E \delta^{3}}{12\left(1-v^{2}\right)}$ is the

flexural rigidity of the casing, where, $E$ is the elastic modulus of the casing, $v$ is the Poisson's ratio of the casing and $\bar{R}=\frac{1}{2}\left(d_{c}+\delta\right)$ is the average radius of the casing.

Equation 2 is a non-homogeneous constant coefficients differential equation of the fourth order, and the solution is:

$$
u(x)=\frac{p_{r}}{8 \beta^{3} E I} e^{-\beta x}(\cos \beta x+\sin \beta x)+\frac{\mu Q x}{2 \pi \delta E l}(x \leq l)
$$

Equation 3 is the radial displacement of casing exerted by the packer slips under $p_{r}$ and $Q$. Because the force was uniform in the derivation process of equation 3 , it can be used to get the stress approximately when the force only exists in the contact surface of casing and slips. With the pressure as $p_{r}$ and length $l$, the displacement of casing inside the slips of packer can be obtained by the principle of elastic superposition and integral method as:

$$
\begin{aligned}
& u(x)=\frac{p_{r}}{8 \beta^{4} E I}\left[2-e^{-\beta x} \cos \beta x-e^{-\beta(l-x)} \cos \beta(l-x)\right](x \leq l) \\
& +\frac{v Q x}{2 \pi \delta E l}
\end{aligned}
$$

The relationship between the inner stress of shell and displacement can be expressed as follows by the theory of cylindrical shell.

$$
\begin{aligned}
& N_{x}=\frac{\partial M_{x}}{\partial x}=-E I \frac{\partial^{3} u}{\partial x^{3}}=\frac{Q x}{2 \pi \bar{R} l} \\
& M_{x}=-E I \frac{\partial^{2} u}{\partial x^{2}}=\frac{p_{r}}{4 \beta^{2}}\left[e^{-\beta x} \sin \beta x+e^{-\beta(l-x)} \sin \beta(l-x)\right] \\
& N_{\varphi}=-\frac{E \delta u}{\bar{R}}=-p_{r} \bar{R}\left[1-\frac{1}{2} e^{-\beta x} \cos \beta x-\frac{1}{2} e^{-\beta(l-x)} \cos \beta(l-x)\right]-\frac{v Q x}{2 \pi \bar{R} l} \\
& M_{\varphi}=-v E I \frac{\partial^{2} u}{\partial x^{2}}=v M_{x}
\end{aligned}
$$

where, $N_{x}$ is the axial force of casing per unit length, $N_{\varphi}$ is the circumferential force per unit circumference, $M_{x}$ is the bending moment per unit axial length, positive when the section bending toward the external side of the shell, but negative in the opposite direction, $M_{\varphi}$ is the circumferential bending moment per unit circumference and the rules of positive or negative are same as above.

To simplify the deduced process, the following functions have been introduced.

$$
\begin{aligned}
& \Psi_{1}(x)=e^{-\beta x} \sin \beta x \\
& \Psi_{2}(x)=e^{-\beta(l-x)} \sin \beta(l-x) \\
& \Psi_{3}(x)=e^{-\beta x} \cos \beta x \\
& \Psi_{4}(x)=e^{-\beta(l-x)} \cos \beta(l-x),
\end{aligned}
$$

$\Psi_{5}(x)=\frac{Q x}{2 \pi \bar{R} l}$.

So, equation 4 and equation 5 can be rewritten as:

$$
\begin{aligned}
& u(x)=\frac{p_{r}}{8 \beta^{4} E I}\left[2-\Psi_{3}(x)-\Psi_{4}(x)\right]+\frac{v \bar{R}}{\delta E} \Psi_{5}(x)(x \leq l) \\
& N_{x}=\Psi_{5}(x) \\
& M_{x}=\frac{p_{r}}{4 \beta^{2}}\left[\Psi_{1}(x)+\Psi_{2}(x)\right] \\
& N_{\varphi}=-p_{r} \bar{R}\left[1-0.5 \Psi_{3}(x)-0.5 \Psi_{4}(x)\right]-v \Psi_{5}(x)(x \leq l) \\
& M_{\varphi}=\frac{v p_{r}}{4 \beta^{2}}\left[\Psi_{1}(x)+\Psi_{2}(x)\right]
\end{aligned}
$$

The curves of stress with $x$ can be drawn based on the equations above, and the dangerous section of the casing exerted by packer slips can be estimated. From the structure of the function $\Psi_{\mathrm{i}}(x)$, we can get the limit value of $M_{x}$ and $N_{\varphi}$ by the extreme value method. From $M_{x}$ in equation 7 , we can obtain

$$
\Psi_{3}(x)+\Psi_{2}(x)=\Psi_{1}(x)+\Psi_{4}(x)
$$

It was obvious that when $x$ was in the middle position of casing, the differential of $M_{x}$ with respect to $x$ was zero. And, it can be found that the bending moment of casing reaches the maximum at the two ends of casing, while reaches the minimum at the middle point with further analysis.

From $N_{\varphi}$ in equation 7, we can obtain

$$
\Psi_{2}(x)+\Psi_{4}(x)-\Psi_{1}(x)-\Psi_{3}(x)=\frac{v Q}{2 \pi \bar{R}^{2} p_{r} \beta l}
$$

From above equations, we can know that the hoop tensile force near the bottom of the Casing exerted by slips reachesthe maximum.

\section{STRESS ANALYSIS OF CASING EXERTED BY SLIPS}

From the above analysis, it can be seen that the bending moment and hoop tensile force near the bottom of casing are maximum, so we should use the stress at this dangerous position to verify the strength safety of casing. The formulas of positive axial stress and positive circumferential stress are:

$$
\begin{aligned}
& \sigma_{1}=\frac{N_{x}}{\delta}+\frac{6 M_{x}}{\delta^{2}}=\frac{1}{\delta} \Psi_{5}(x)+\frac{3 p_{r}}{2 \delta^{2} \beta^{2}}\left[\Psi_{1}(x)+\Psi_{2}(x)\right] \\
& \sigma_{2}=\frac{N_{\varphi}}{\delta}+\frac{6 M_{\varphi}}{\delta^{2}}=\frac{N_{\varphi}}{\delta}+\frac{6 \mu \mathrm{M}_{x}}{\delta^{2}}=-\frac{p_{r} \bar{R}}{\delta}\left[1-0.5 \Psi_{3}(x)-0.5 \Psi_{4}(x)\right] \\
& -\frac{v}{\delta} \Psi_{5}(x)+\frac{3 v p_{r}}{2 \delta^{2} \beta^{2}}\left[\Psi_{1}(x)+\Psi_{2}(x)\right]
\end{aligned}
$$

The stress at the dangerous position can be obtained by the strength theory as follows [13]: 


$$
\begin{aligned}
& \sigma_{\mathrm{xd}}=\frac{p_{r} \bar{R}}{\delta}\left[1-0.5 \Psi_{3}(x)-0.5 \Psi_{4}(x)\right]+ \\
& \frac{1+v}{\delta} \Psi_{5}(x)+\frac{3(1-v) p_{r}}{2 \delta^{2} \beta^{2}}\left[\Psi_{1}(x)+\Psi_{2}(x)\right]
\end{aligned}
$$

The maximum of the stress can be obtained when the derivative of $\sigma_{\mathrm{xd}}$ with respect to $x$ was 0 .

$$
\left(\sigma_{\mathrm{xd}}\right)_{\max }=Q\left[0.556 \cdot\left(1+\frac{d_{c}}{\delta}\right) \cdot \frac{K}{n l d_{c} \sin \beta}-\frac{0.243 \beta}{l}+\frac{0.414}{\left(d_{c}+\delta\right) \delta}\right]
$$

Here, the Poisson's ratio is 0.3 .

\section{ANALYSIS OF THE LIMIT SETTING FORCE EXERTED BY THE PACKER'S SLIPS ON THE CASING}

From equation 13, we can obtain the formula of the limit setting force of exerted by packer's slips on the casing as follows:

$$
Q=\frac{\sigma_{s}}{0.556 \cdot\left(1+\frac{d_{c}}{\delta}\right) \cdot \frac{K}{n l d_{c} \sin \beta}-\frac{0.243 \beta}{l}+\frac{0.414}{\left(d_{c}+\delta\right) \delta}}
$$

where, $\sigma_{s}$ is the yield strength of the material of the casing .

\section{EXAMPLE OF LIMIT SETTING FORCE OF CASING EXERTED BY SLIPS BASED ON CYLINDRICAL SHELL THEORY}

In the example, $51 / 2^{\prime \prime}$ packer was set into casing with outer diameter as $139.7 \mathrm{~mm}$, variable thicknesses as $6.99 \mathrm{~mm}$, $7.72 \mathrm{~mm}, 9.17 \mathrm{~mm}, 10.54 \mathrm{~mm}, 12.09 \mathrm{~mm}, 13.46 \mathrm{~mm}$, steel grade as N80, P110, TP140. The number of slips was 6 , the wedge angle was $15^{\circ}$, the length of the slip teeth was $110 \mathrm{~mm}$, the face angle of slip teeth was $50^{\circ}$, the transverse load coefficient was 3 , and the Poisson's ratio was 0.3 . The curve of limit setting force of the casing exerted by slips of packer calculated by the method is mentioned in this paper, and the thick-wall theory with the thickness of casing is plotted in Fig. (1). In the figure, solid line shows the value calculated by the thick-wall cylinder and the dotted line shows the value calculated by the thin-wall cylinder.

From Fig. (1), we can see that the limit setting force of casing exerted by slips increase in the thickness of casing and increases with the decrease of the inner diameter of casing when the packer and the outer diameter of casing remained constant. The limit setting force was higher in high grade casing, that is to say, the limit setting force of TP140 casing was the biggest of all, while the limit setting force of N80 casing was the least of all. Because of ignoring the bending moment and axial tensile load, the value of limit setting force calculated by thick-wall theory was increased by $5 \%$ to $14 \%$ than the method used in this paper.

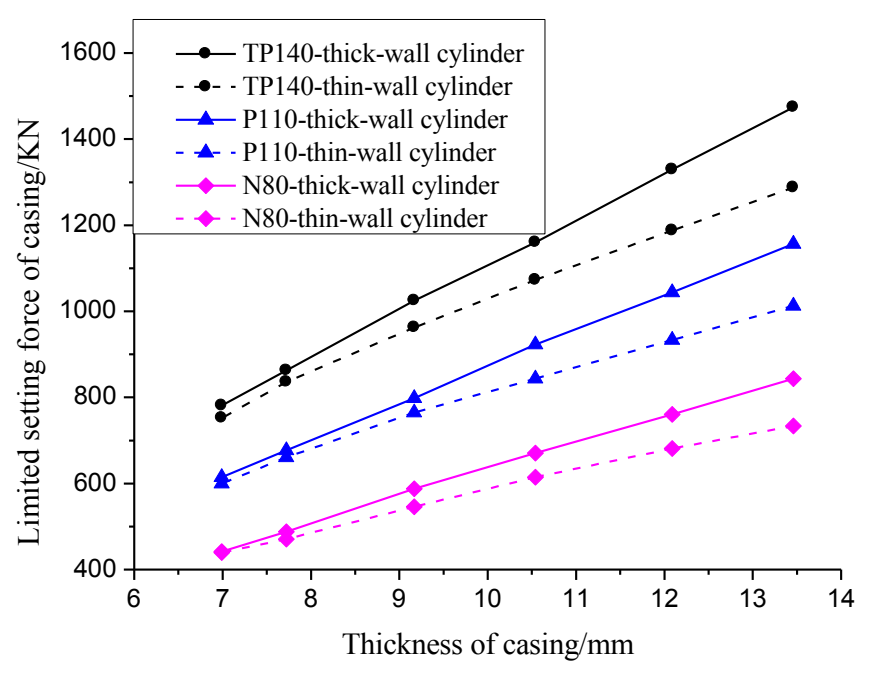

Fig. (1). Limit setting force of the casing exerted by slips of packer with the thickness of casing.

\section{CONCLUSION}

The equation of limit setting force of casing exerted by slips of packer was deduced by the theory of strength and the bending moment of cylindrical shell with the consideration of the axial force and additional bending moment induced by the bending of casing near the slips of packer. The relationships of the limit setting force of N80, P110, TP140 casing and thickness were analyzed and, some conclusions were drawn from the example.

1. The bending stress and the hoop stress were the largest near the bottom of the slips, and that position was the dangerous section. So, we should use the stress at this dangerous position to verify the strength safety of casing.

2. The limit setting force of the casing exerted by slips increased with the thickness of casing when the packer and the outer diameter of casing kept the same.

3. The limit setting force was higher in high grade casing, or to say, the limit setting force of TP140 casing was the biggest of all, while the limit setting force of N80 casing was the smallest of all.

4. With the consideration of the axial force and additional bending moment induced by the bending of casing near the slips of packer, the limit setting force calculated in this paper was decreased by $5 \%$ to $14 \%$ than by thick-wall theory, and it is deemed safer.

\section{CONFLICT OF INTEREST}

The authors confirm that this article content has no conflict of interest.

\section{ACKNOWLEDGEMENTS}

Natural Science Foundation of Shaanxi Province, China (Grant No. 2014JQ7289); Important National Science \& Technology Specific Project (Grant No.2011ZX05046-04); National Natural Science Foundation of China (Grant No.51374171). 


\section{REFERENCES}

[1] D. Yang, Y. Dou, and A. Xu, "The causes of losing seal and countermeasures of the acid fracturing packer of the high temperature and high pressure deep well. Petroleum Machinery, 36(9), 129-131, 2008.

[2] Y. Dou, H. Xu, X. Jiang, et al. "Broken Reason of center tube of packer in the combination work of perforating and testing", Petroleum Machinery, 35(9), 113-115, 2007.

[3] Y. Zhao, "Stress analysis and theoretical calculation of the slip packer", Oil Drilling \& Production Technology, 10(2): 69-72, 1983.

[4] D. Wang, S. He, and X. Zhang, "Research on the contact stress of packer slips", Experimental Mechanics, 21(3), 351-356, 2006.

[5] J. Zhang, R. Liu, L. Li, et al. "Optimization and experiment of integral slip tooth profile", Petroleum Machinery, 40(6), 83-86, 2012.
[6] T. Liu, and H. Xie, "simulated test research on casing failure caused by anchor packer", Oil Field Equipment, 30(2), 49-51, 2001.

[7] S. Zhou, "Calculation of the limited load-bearing capacity of the pipe string inside a slip", Journal of Xi'an Petroleum Institute, 16(2), 50-54, 2001.

[8] X. Cui, and H. Zhang, "Calculation of the load-bearing capacity of the pipe string inside a slip", Acta Petrolei Sinica, 21(1), 8790, 2000.

[9] Tool Pusher's. 9th edition. API Drill-pipe standards. Care and handing section B-3. API Publication, Washing D.C, 1981.

[10] Spec API. 5CT. Specification for casing and tubing, 2001.

[11] API T R. 5C3. Technical Report on Equations and Calculations for Casing, Tubing, and Line Pipe Used as Casing or Tubing; and Performance Properties Tables for Casing and Tubing 2008.

[12] Z. Xu. Elastic mechanics tutorial. Beijing: Higher Education Press, 1984.

[13] H. Liu. Mechanics of materials. Beijing: Higher Education Press, 1982.

(C) Cao et al.; Licensee Bentham Open.

This is an open access article licensed under the terms of the Creative Commons Attribution Non-Commercial License (http://creativecommons.org/licenses/ by-nc/4.0/) which permits unrestricted, non-commercial use, distribution and reproduction in any medium, provided the work is properly cited. 